\title{
Cochlear implantation in South Africa (part 2)
}

\author{
A Bhamjee, ${ }^{1}$ MA (Audiology) (D; F Mahomed-Asmail, ${ }^{1}$ DPhil (Communication Pathology); J Perold, ${ }^{2}$ MSc (Audiology); J W Loock, ${ }^{3}$ MB \\ ChB; T le Roux, ${ }^{1}$ DPhil (Communication Pathology) \\ ${ }^{1}$ Department of Speech-Language Pathology and Audiology, Faculty of Humanities, University of Pretoria, South Africa \\ ${ }^{2}$ Tygerberg Hospital Stellenbosch University Cochlear Implant Unit, Cape Town, South Africa \\ ${ }^{3}$ Division of Otorhinolaryngology, Faculty of Medicine, Stellenbosch University, Cape Town, South Africa
}

Corresponding author: T le Roux (talita.leroux@up.ac.za)

Cochlear implantation is a timeous and cost-effective solution for severe-to-profound sensorineural hearing loss (SNHL) and has transformed the lives of many individuals with significant hearing loss. The advent of cochlear implantation has meant that, for the first time, one of the senses (hearing), having been entirely lost, can be restored. The previous article in this series sketched the problem of severe-toprofound SNHL, and how cochlear implantation can overcome this, how a cochlear implant (CI) works, the history of cochlear implantation and the principles of the multidisciplinary CI team. The current status of cochlear implantation in South Africa (SA) is the subject of discussion in this article, the second of this two-part series on cochlear implantation. It comprises a study of the best available current data on the status of $\mathrm{CI}$ in SA.

S Afr Med J 2021;112(2):71-75. https://doi.org/10.7196/SAMJ.2022.v112i2.16018

There are currently 12 independent cochlear implant (CI) programmes in South Africa (SA), all affiliated with the South African Cochlear Implant Group (SACIG) - a professional body representing all CI professionals and programmes in SA. ${ }^{[1]}$ These established CI programmes are representative of five SA provinces, namely Gauteng Province, which has five CI programmes, the Western Cape Province, which has three CI programmes, the Eastern Cape Province, which has two CI programmes and the Free State and KwaZulu-Natal Provinces, which each have one CI programme. Five of the 12 CI programmes are situated within the private healthcare sector and three within the public healthcare sector, and four are combined private and public (fully/partially public) sector CI programmes. Thus a significant challenge in SA is the uneven geographic distribution and unequal accessibility of the CI programmes in terms of private v. public healthcare, with private programmes accounting for the majority of the CI programmes.

\section{National regulation and the SACIG quality standards}

Hearing-impaired people, and children in particular, are a vulnerable group. As CI outcomes became well established and grew in SA, it soon became evident that there was a need for guidance and/or regulation of the healthcare professionals involved in cochlear implantation. This led to the formation of the SACIG, with the stated aim of encouraging the interchange of ideas and information between anyone involved, or interested in, any aspect of CIs, providing comprehensive advice on CIs and quality standards in collaboration with its members and sharing best practice with the services in which they work, and providing guidelines in setting, upholding and maintaining standards of service by all professionals that form part of CI service delivery. ${ }^{[1]}$

There is no national body with regulatory authority over cochlear implantation in SA other than the Health Professionals Council of SA (HPCSA). SACIG's role then is one of guidance, facilitation, advice and support.
SACIG has developed a comprehensive set of quality standards in a document to guide the minimum standards that providers of CIs in SA should adhere to, based on international standards of best practice..$^{[1-3]}$ The document describes the target patient group (indications for $\mathrm{CI}$ ), the $\mathrm{CI}$ team (professionals required), facilities required, selection criteria, proper procedures (preoperatively through to rehabilitation and long-term management), patient referrals and transfers, dealing with CI-related problems, and auditing. SACIG holds an annual meeting to promote the sharing of knowledge, co-operation and collegial interaction among workers in the field. Each CI programme in SA is requested to submit an annual report to SACIG in which clinical activity, staffing levels, patient performance outcomes, device failures, medical/surgical complications and research interests and outcomes are addressed. ${ }^{[1]}$

\section{Cochlear implant outcomes and data management in SA}

Systematically captured and reported national CI data are required to guide CI policy-makers, assist in gaining increased legislative support for CIs and promote evidence-based service delivery.

In general, there are limited published data on cochlear implantation in SA, and national outcome data were published only recently. ${ }^{[4-7]}$ The limited published reports available on outcomes for paediatric and adult cochlear implantation in SA do, however, indicate positive outcomes for both paediatric ${ }^{[4,6]}$ and adult ${ }^{[5]} \mathrm{CI}$ recipients.

The only source of information on the general status of cochlear implantation in SA is through SACIG's annual reports. Until now, this information has not been systematically collated.

The main author of this article undertook to provide an overview of CIs in SA through a retrospective review of the 2019 annual reports submitted to SACIG by the CI programmes. These data provide a cross-section of the status of CI in SA at the current time. Two of the $12 \mathrm{CI}$ programmes' annual reports were unfortunately not accessible.

Institutional ethics committee approval was obtained prior to the commencement of data collection (ref. no. HUM005/1019). 


\section{The professionals involved in cochlear implantation in SA}

Each professional on the CI team should be appropriately qualified, be registered with their professional body, comply with HPCSA requirements, attend the SACIG meetings regularly, and ensure their continuous professional development. ${ }^{[1]}$ Furthermore, audiologists working with CI patients are required by the HPCSA to complete the 'Short course in additional training in cochlear implant MAPping and rehabilitation accredited by the HPCSA' and 60 hours of supervised mentoring before working independently with CI patients. SACIG's guidelines on the professionals who should constitute a CI programme align with international guidelines on quality standards for adult and paediatric cochlear implantation. ${ }^{[2,3]}$

For the year 2019, all CI programmes for which data were available comprised of multidisciplinary teams involving the recommended core personnel (Table 1). Therefore, the $\mathrm{CI}$ team structures in SA are adequate in accordance with international standards.

\section{National cochlear implantation statistics}

Table 2 summarises 2019 national cochlear implantation statistics in SA across the $10 \mathrm{CI}$ programmes for which data were available for paediatric and adult CI recipients.

Based on available annual report data, from the year 1986 up to the end of 2019, approximately 2877 cochlear implantations were performed in SA, and there were approximately $2286 \mathrm{CI}$ recipients. The number of cochlear implantations performed exceeds the number of $\mathrm{CI}$ recipients, as some $\mathrm{CI}$ recipients were implanted bilaterally.

\section{Patients evaluated for cochlear implantation}

It can be confidently suggested that only a fraction of the patients with severe-to-profound sensorineural hearing loss (SNHL) in SA who would audiologically qualify for a CI are referred for implantation. This is a global problem. A recent study conducted at Vanderbilt University in the USA found that only $5 \%$ of patients meeting the audiological criteria for cochlear implantation were referred to a CI programme. ${ }^{\left[{ }^{[8]}\right.}$ Furthermore, CIs remain underused worldwide ${ }^{[9]}$ despite their reported success. ${ }^{[10,11]}$ Under $10 \%$ of adults with severe or worse hearing loss use CIs in Australia, ${ }^{[12]} \sim 8 \%$ in the USA $^{[8]}$ and $<5 \%$ in the UK. ${ }^{[13]}$

In 2019, only 318 patients were referred for cochlear implantation in SA. Possible reasons for the low referral rate include health professionals' limited awareness of CI candidacy criteria, and lack of clarity about referral pathways and when to refer patients for CI evaluation. ${ }^{[8]}$ Geographical constraints and the uneven distribution of $\mathrm{CI}$ teams across the country also potentially affect referrals to CI programmes, as do socioeconomic disparities and challenges such as unemployment, inability to attend appointments due to work responsibilities, and limited parental insight into the necessary timeous audiological intervention required. ${ }^{[8]}$

\section{Candidacy criteria and reasons for non-selection}

In 2019 , of the 318 patients referred for CI assessment, only $52.52 \%$ $(n=167)$ received implants. Table 3 demonstrates the most common reasons for the non-selection of potential CI candidates for the year 2019. The reasons for non-implantation outlined in Table 3 reflect the social, economic and healthcare realities of SA.

\section{Delayed referral for cochlear implantation in the paediatric population}

According to available data, patient age as a reason for CI nonselection accounted for $15.2 \%$ of the referred cases in 2019 . Candidates for paediatric cochlear implantation need to be implanted early ( $<3.5$ years old) to benefit from the critical period of neural plasticity in order to develop speech and language skills comparable with their normal-hearing counterparts. ${ }^{[14-16]}$ Moreover, compelling evidence suggests that early implantation, particularly $<12$ months of age, results in better outcomes for children with prelingual, permanent childhood hearing loss. ${ }^{[17]}$

Paediatric cochlear implantation is considered delayed when it is performed $>12$ months after the hearing loss has been diagnosed. ${ }^{[17,18]}$ Delayed paediatric cochlear implantation not only negatively impacts speech and language development, but also increases the likelihood of the child being enrolled in a non-mainstream educational setting. ${ }^{[4]}$

Table 1. Professionals involved in cochlear implantation in South Africa $(N=118)^{*}$

\begin{tabular}{ll}
\hline Professionals & Total, $\boldsymbol{n}(\%)$ \\
\hline Audiologists & $44(37.29)$ \\
Otorhinolaryngologists & $29(24.58)$ \\
Rehabilitationists (such as speech-language therapists, auditory-verbal therapists) & $26(22.03)$ \\
Other (such as geneticists, psychologists, radiologists, bio-engineers, social workers) & $19(16.10)$ \\
&
\end{tabular}

Table 2. National cochlear implantation statistics in South Africa*

\begin{tabular}{|c|c|c|}
\hline 2019 & Paediatric, $n(\%)$ & Adult, $n(\%)$ \\
\hline Patients referred for cochlear implantation $(N=318)$ & $101(31.76)$ & $217(68.24)$ \\
\hline CI recipients for the year $2019(n=167)^{\dagger}$ & $61(36.53)$ & $106(63.47)$ \\
\hline Total cochlear implantations (devices) for $2019(n=216)^{\dagger}$ & $93(43.06)$ & $123(56.94)$ \\
\hline \multicolumn{3}{|l|}{ Historical data (until end of 2019) } \\
\hline Total CI recipients in SA $(n=2286)^{\dagger}$ & $1239(54.20)$ & $1047(45.80)$ \\
\hline Total cochlear implantations (devices) in SA & \multicolumn{2}{|c|}{$2877^{\dagger}$} \\
\hline
\end{tabular}


In $\mathrm{SA}$, recent reports have revealed significant delays in the age at paediatric cochlear implantation. ${ }^{[19,20]}$ These delays are affected by the delayed diagnosis of hearing loss as well as delays between hearing loss diagnosis and eventual cochlear implantation. ${ }^{[19,20]}$

The most significant factor contributing to delayed hearing loss diagnosis is the paucity of newborn hearing screening (NHS) programmes in SA. NHS is a viable means of reducing the burden of hearing loss and efficiently identifying serious childhood hearing problems when these problems can be treated most adequately. ${ }^{[21-23]}$ The challenge, however, is that research on NHS in SA has projected that $<10 \%$ of the $>1$ million infants born in SA each year are likely to have their hearing screened. ${ }^{[24,25]}$ A lack of NHS programmes contributes significantly towards delays in the diagnosis of hearing loss. This delay in diagnosis results in a delay in initial hearing-aid fitting and, therefore, a delay in subsequent cochlear implantation. Thus the necessary early auditory stimulation and appropriate intervention required for optimal outcomes for children with severeto-profound SNHL are not typically realised, thereby predisposing this population to poorer outcomes.

Factors contributing toward delayed implantation include delayed referrals to specialised CI programmes, limitations in CI funding, geographical constraints, inequitable access to healthcare, limited appropriate rehabilitation resources and referrals post diagnosis and parental factors such as difficulty in attending CI appointments due to work commitments, indecisiveness about proceeding with the CI, and/or opting for second opinions. ${ }^{[19,20,26]}$

\section{Socioeconomic challenges for cochlear implantation}

The expense of cochlear implantation is not only in the initial funding of the device but also in the provision of the required ongoing support and intervention services. Therefore, it is understandable that the potential CI recipient or parent/caregiver's ability to demonstrate a commitment toward this long-term rehabilitation process is a critical deciding factor in CI selection.
Various post-implantation challenges are encountered by CI recipients and their families. Beside the long-term costs associated with the maintenance of the $\mathrm{CI}$ device, additional post-implantation parent-perceived CI challenges recently reported include access to specialised support services, the long-term commitment to the ongoing rehabilitation required and language and educational challenges (sourcing appropriate educational settings for their cochlear-implanted children). ${ }^{[20]}$ Increased financial, educational and rehabilitative support to CI recipients and their families is required, but is not always attainable in the SA context.

\section{Sources of funding for cochlear implantation}

Cochlear implantation is expensive, but ultimately extremely costeffective. ${ }^{[26,27]}$ The cost of cochlear implantation refers to the funding of the CI device. Table 4 demonstrates the various sources of funding for the year 2019 across the 10 CI programmes for which data were available.

The SA health system is divided in two. ${ }^{[26]}$ Indeed, it is perhaps wrong to refer to a SA health system, suggesting that there is a single system when there are, in fact, two systems. The majority of the SA population $(84 \%)$ are reliant on public healthcare sector services, ${ }^{[28]}$ where rehabilitative interventions such as CIs are not prioritised and compete with life-threatening conditions such as HIV/AIDS and tuberculosis. ${ }^{[26]}$ By contrast, only $16 \%$ of the population belongs to SA's self-funded private healthcare sector. ${ }^{[28]}$ Yet, despite these population numbers, in the year under review, $74.53 \%$ of CIs were partly or completely funded by medical aids, and less than a fifth (19.91\%) were government funded. In most parts of the country, access to a private medical aid or sufficient finances is a prerequisite for access to the CI device and procedure. ${ }^{[26]}$ This is, to an extent, understandable, given the context of the healthcare burden on the state and the expense of CIs. It should always be remembered that the expenses involved in CI include not only the initial funding of the CI system, but also long-term maintenance of the device (including

Table 3. Reasons for non-selection of CI candidates $(N=125)^{*+}$

\begin{tabular}{|c|c|}
\hline Reason & $n(\%)$ \\
\hline Patient choice (candidates/parents opted not to proceed with implantation despite meeting selection criteria) & $36(28.8)$ \\
\hline $\begin{array}{l}\text { Socioeconomic factors (for example, financial implications hindering cochlear implantation, geographical constraints and } \\
\text { compliance and commitment towards the CI process) }\end{array}$ & $30(24)$ \\
\hline Outside audiological criteria (hearing loss did not meet the audiological criteria for cochlear implantation) & $22(17.6)$ \\
\hline Patient age (implanting older paediatric candidates ( $>3.5$ years) with congenital hearing loss may lead to poorer outcomes) & $19(15.2)$ \\
\hline Other & $18(14.4)$ \\
\hline
\end{tabular}

Table 4. Sources of funding for cochlear implantation $(N=216)^{*}$

\begin{tabular}{|c|c|c|c|}
\hline Source of funding & Total, $n(\%)$ & $\begin{array}{l}\text { Proportion } \\
\text { children, } n(\%)\end{array}$ & $\begin{array}{l}\text { Proportion } \\
\text { adults, } n(\%)\end{array}$ \\
\hline Medical aid and other sources (private funding, donations, charity, etc.) & $96(44.44)$ & $40(41.67)$ & $56(58.33)$ \\
\hline Medical aid only & $65(30.09)$ & $21(32.31)$ & $44(67.69)$ \\
\hline Government (public healthcare sector) funding & $43(19.91)$ & $23(53.49)$ & $20(46.51)$ \\
\hline Charity & $5(2.31)$ & $5(100)$ & 0 \\
\hline Private funding (no medical aid) & $4(1.85)$ & $3(75)$ & $1(25)$ \\
\hline Donated by a CI company & $3(1.39)$ & $1(33.33)$ & $2(66.67)$ \\
\hline Total & 216 & 93 & 123 \\
\hline
\end{tabular}


the costs for procuring batteries, spare parts, upgrades required for the speech processor, external repairs as well as the lifetime of routine $\mathrm{CI}$ device programming sessions that are required). ${ }^{[5,20,26]}$ This means that a patient who has no income with which to maintain the device after implantation cannot be considered a candidate for implantation - a 'Catch-22' situation, as this then perpetuates their extremely limited employment options. The financial implications of cochlear implantation, including CI device maintenance, were the primary concerns expressed by parents of paediatric CI recipients in SA in a recently reported study. ${ }^{[20]}$

However, definite inroads have been made and continue to be made into providing cochlear implantation in the public sector. In 2019, five CI programmes had specific allocations for CI to state patients with no medical aid, and 43 public healthcare sector patients were implanted in 2019. This is a significant improvement on the situation of a few years ago.

\section{Unilateral v. billateral implantation}

In light of the realities described above, bilateral implantation of an individual could be considered an additional moral dilemma. Nevertheless, there is evidence that bilaterally implanted paediatric CI recipients demonstrate improved health-related quality of life, ${ }^{[29-31]}$ localisation abilities, ${ }^{[29,32]}$ improved speech recognition in quiet ${ }^{[33,34]}$ and in noise $\mathrm{e}^{[29,35,36]}$ and notably better language outcomes ${ }^{[37]}$ compared with their unilaterally implanted peers. Bilateral implantation is therefore the standard of care for children with severe-to-profound SNHL in most developed countries. ${ }^{[37,38]}$ Similarly, improved outcomes for bilaterally implanted adults, as compared with unilaterally implanted adults, have also been widely reported. ${ }^{[39-41]}$ However, in low- to middle-income countries (LMICs) such as SA, in almost all instances, funding of the second implant remains the responsibility of the individual or parents/caregivers, and therefore, access to bilateral implantation is a challenge encountered by both paediatric and adult CI recipients in SA. ${ }^{[5,19]}$ In a recent study on paediatric cochlear implantation in SA, more than two-thirds of the parents of unilaterally implanted paediatric CI recipients indicated a desire for their child to receive a second implant. ${ }^{[20]}$ However, the financial costs related to funding the second implant system and the long-term costs associated with device maintenance hindered acquiring a second implant. ${ }^{[20]}$ This, therefore, results in inequitable access to bilateral implantation, where only financially able individuals or parents/ caregivers can afford a second implant.

\section{Strengths and limitations of this study}

This article provides the first national overview of cochlear implantation in SA. The authors acknowledge the limitation of an incomplete dataset, since comprehensive annual report data were unfortunately not available for 2 of the 12 CI programmes in SA. Additionally, owing to limited and missing data in some of the annual reports and the possibility of inconsistencies in these reports, it is possible that there might be some data inaccuracies.

\section{Conclusion}

An expanding number of cochlear implantations performed countrywide, and the increasing number of CI programmes (in both the public and private sectors) and of professionals involved in cochlear implantation, demonstrate remarkable progress in the field of cochlear implantation. A particularly gratifying aspect is evidence of 'green shoots' for cochlear implantation in the public sector.

There is a desperate need for the introduction of universal NHS in SA so that this life-changing intervention can be provided to those who arguably need it most - children born with severe-to- profound hearing loss. There is also a need for an increased number of NHS programmes, particularly in locations where programmes do not exist, and in the public sector. So too is improved financial, educational and rehabilitative support for CI recipients needed. Increasing access to sustainable hearing healthcare resources such as CIs will undoubtedly contribute toward effectively addressing the global burden of disabling hearing loss at a SA national level. This should be done by promoting awareness and advocating for appropriate hearing healthcare in SA, advancing toward a reduction in the risk factors that contribute towards disabling hearing loss and through the promotion of effective early identification and intervention services. ${ }^{[42]}$ To achieve these goals and adequately address the global burden of disabling hearing loss in LMICs such as SA, substantial and sustainable hearing healthcare resources and services are required across the country's healthcare sector.

Declaration. None.

Acknowledgments. The authors appreciatively acknowledge Tamara van Zyl (SACIG secretary) for her assistance and valued support with the SACIG annual report statistics.

Author contributions. AB drafted the article. All authors read, edited and approved the article.

Funding. This project was funded with assistance from the Andrew W Mellon Foundation's grant entitled 'Supra-institutional initiative on the advancement of black South Africans within the arts, humanities, and social sciences', grant number G-41500687.

Conflicts of interest. None.

1. South African Cochlear Implant Group. Quality standards for cochlear implantation in South Africa, 2020. http://www.sacig.org.za/wp-content/uploads/2020/01/SACIG-Guidelines.pdf (accessed 20 May 2020).

Martin J, Raine CH. Quality standards for cochlear implantation in children and young adults. Cochlear 2. Martin J, Raine CH. Quality standards for cochlear implantation in children and young
Implants Int 2013;14(Suppl 2):S13-S20. https://doi.org/10.1179/1467010013Z.00000000099

3. Müller J, Raine CH. Quality standards for adult cochlear implantation. Cochlear Implants Int Müller J, Raine CH. Quality standards for adult cochlear implantation.
2013;14(Suppl 2):S6-S12. https://doi.org/10.1179/1467010013Z.00000000097

2013;14(Supp1 2):S6-S12. https://doi.org/10.1179/1467010013Z.00000000097 4. Le Roux T, Vinck B, Butler I, et al. Predictors of pediatric cochlear implantation outcon
J Pediatr Otorhinolaryngol 2016;84:61-70. https://doi.org/10.1016/j.ijporl.2016.02.025

5. Le Roux T, Vinck B, Butler I, et al. Predictors of health-related quality of life in adult cochlear implant recipients in South Africa. Int J Audiol 2017;56(1):16-23. https://doi.org/10.1080/14992027.2016.1 227482

6. Brewis B, le Roux T, Schlemmer K, Nauta L, Vinck B. Health-related quality of life in South African children who use cochlear implants. Int J Audiol 2020;59(2):132-139. https://doi.org/10.1080/14992027.2019.1661531 . Lenarz T, Muller L, Czerniejewska-Wolska H, et al. Patient-related benefits for adults with cochlear implantation: A multicultural longitudinal observational study. Audiol Neurotol 2017;22(2):61-73. https:// doi.org/10.1159/000477533

8. Holder JT, Reynolds SM, Sunderhaus LW, Gifford RH. Current profile of adults presenting for preoperative cochlear implant evaluation. Trends Hearing 2018;22:1-16. https://doi.org/10.1177/2331216518755288

9. Sorkin DL, Buchman CA. Cochlear implant access in six developed countries. Otol Neurotol 9. Sorkin DL, Buchman CA. Cochlear implant access in six devel
2016:37(2):el61-el64. https://doi.org/10.1097/MAO.0000000000000946

10. Gaylor GM, Raman G, Chung M, et al. Cochlear implantation in adults: A systematic review and meta-analysis. JAMA Otolaryngol Head Neck Surg 2013;139(3):265-272. https://doi.org/10.1001/ jamaoto.2013.1744

11. Aimoni C, Ciorba A, Hatzopoulos S, et al. Cochlear implants in subjects over age 65: Quality of life and audiological outcomes. Med Sci Monit 2016;22:3035-3042. https://doi.org/10.12659/msm.896869

12. Access Economics. The economic impact and cost of hearing loss in Australia. 2006. https://hearnet.org.au/ wp-content/uploads/2015/10/ListenHearFinal.pdf (accessed 5 August 2021).

13. Raine C. Cochlear implants in the United Kingdom: Awareness and utilisation. Cochlear Implants Int 2013;14(Suppl 1):S32-S37. https://doi.org/10.1179/1467010013Z.00000000077

14. Wilson BS, Dorman MF. Cochlear implants: A remarkable past and a brilliant future. Hear Res 2008;242(1-2):3-21. https://doi.org/10.1016/j.heares.2008.06.005

15. Sharma A, Dorman MF, Spahr AJ. A sensitive period for the development of the central auditory system in children with cochlear implants: Implications for age of implantation. Ear Hear 2002;23(6):532-539. https:// doi.org/10.1097/00003446-200212000-00004

16. Leigh J, Dettman S, Dowell R, Briggs R. Communication development in children who receive a cochlear implant by 12 months of age. Otol Neurotol 2013;34(3):443-450. https://doi.org/10.1097/
coligh cochlear implant by 12

17. Armstrong $\mathrm{M}$, Maresh $\mathrm{A}$, Buxton $\mathrm{C}$, et al. Barriers to early pediatric cochlear implantation. Int J Pediatr Otorhinolaryngol 2013;77(11):1869-1872. https://doi.org/10.1016/j.ijporl.2013.08.031

18. Fitzpatrick E, Ham J, Whittingham J. Pediatric cochlear implantation: Why do children receive implants late? Ear Hear 2015;36(6):688-694. https://doi.org/10.1097/AUD.0000000000000184

19. Le Roux T, Swanepoel DW, Louw A, Vinck B, Tshifularo M. Profound childhood hearing loss in a South Africa cohort: Risk profile, diagnosis and age of intervention. Int J Pediatr Otorhinolaryngol 2015;79(1):8-14. https://doi.org/10.1016/.i.jporl.2014.09.033

20. Bhamjee A, le Roux T, Schlemmer K, et al. Parent-perceived challenges related to the pediatric cochlear implantation process and support services received in South Africa. Int J Pediatr Otorhinolaryngol 2019;126:1-10. https://doi.org/10.1016/j.ijporl.2019.109635

21. Joint Committee on Infant Hearing (JCIH). Year 2007 position statement: Principles and guidelines for early hearing detection and intervention programs. Pediatrics 2007;120(4):899-921. https://doi.org/10.1542/ peds. 2007-2333 
22. Pimperton $\mathrm{H}$, Blythe $\mathrm{H}$, Kreppner $\mathrm{J}$, et al. The impact of universal newborn hearing screening on long-term literacy outcomes: A prospective cohort study. Arch Dis Child 2016;101(1):9-15. https://doi.org/10.1136/ literacy outcomes: A prosp
archdischild-2014-307516

23. Olusanya BO, Luxon LM, Wirz SL. Benefits and challenges of newborn hearing screening for developing countries. Int J Pediatr Otorhinolaryngol 2004;68(3):287-305. https://doi.org/10.1016/jijporl.2003.10.015

24. Meyer ME, Swanepoel DW, le Roux T, van der Linde M. Early detection of infant hearing loss in the private health care sector of South Africa. Int J Pediatr Otorhinolaryngol 2012;76(5):698-703. https://doi. org/10.1016/j.ijporl.2012.02.023

25. Theunissen M, Swanepoel D. Early hearing detection and intervention services in the public health sector in South Africa. Int J Audiol 2008;47(1):23-29. https://doi.org/10.1080/14992020802294032

26. Kerr G, Tuomi S, Müller A. Costs involved in using a cochlear implant in South Africa. South African J Commun Disord 2012;59(1):16-26. https://doi.org/10.4102/sajcd.v59i1.18

27. Emmett SD, Tucci DL, Smith M, et al. GDP matters: Cost effectiveness of cochlear implantation and Deaf education in sub-Saharan Africa. Otol Neurotol 2015;36(8):1357-1365. https://doi.org/10.1097/ MAO.0000000000000823

28. Mayosi BM, Benatar SR. Health and health care in South Africa - 20 years after Mandela. N Engl J Med 2014;371(14):1344-1353. https://doi.org/10.1056/NEJMsr1405012

29. Lovett RES, Kitterick PT, Hewitt CE, Summerfield A. Bilateral or unilateral cochlear implantation for deaf children. An observational study Arch Dis Child 2010;95(2):107-112, https//doiorg/10.1136/ adc. 2009.160325

30. Sparreboom M, Leeuw AR, Snik AFM, Mylanus EAM. Sequential bilateral cochlear implantation in children: Parents' perspective and device use. Int J Pediatr Otorhinolaryngol 2012;76(3):339-344. https://doi. org/10.1016/j.ijporl.2011.12.004

31. Galvin KL, Mok M. Everyday listening performance of children before and after receiving a second cochlear implant: Results using the parent version of the speech, spatial, and qualities of hearing scale. Ear Hear 2016;37(1):93-102. https://doi.org/10.1097/AUDeopor

32. Van Schoonhoven J, Sparreboom M, van Zanten BG, et al. The effectiveness of bilateral cochlear implants for severe-to-profound deafness in children: A systematic review. Otol Neurotol 2010;31(7):1062-1071. https:// doi.org/10.1097/MAO.0b013e318278506
33. Scherf $\mathrm{F}$, van Deun $\mathrm{L}$, van Wieringen A, et al. Hearing benefits of second-side cochlear implantation in two groups of children. Int J Pediatr Otorhinolaryngol 2007;71(12):1855-1863. https://doi.org/10.1016/ji.jporl.2007.08.012

34. Zeitler DM, Kessler MA, Terushkin V, et al. Speech perception benefits of sequential bilateral cochlea implantation in children and adults: A retrospective analysis. Otol Neurotol 2008;29(3):314-325. https://doi org/10.1097/MAO.0b013e3181662 cb5 35. Van Deun L, Van Wieringen A, Wouters J. Spatial speech perception benefits in young children with normal hearing and cochlear implants. Ear Hear 2010;31(5):702-713. https://doi.org/10.1097/AUD.0b013e3181e40dfe 6. Litovsky R., J ohnstone PM, Godar SP. Benefits of bilateral cochlear implants and/or
Int J Audiol 2006;45(Suppl 1):S78-S91. https:///oi.org/10.1080/14992020600782956

Int Judiol 2006;45(Suppl I):S78-S91. https://doi.org/10.1080/14992020600782956 in children. Ear Hear 2014;35(4):396-409. https://doi.org/10.1097/AUD.0000000000000022

2014;35(4):396-409. https:///doi.org/10.1097/AU D. 0000000000000022 . Tait M, Nikolopoulos TP, De Raeve L, et al. Bilateral versus unilateral cochlear implantation in young
children. Int J Pediatr Otorhinolaryngol 2010;74(2):206-211. https://doi.org/10.1016/j.ijporl.2009.11.015

39. Härkönen K, Kivekäs I, Rautiainen M, Kotti V, Sivonen V, Vasama JP. Sequential bilateral cochlear implantation improves working performance, quality of life, and quality of hearing. Acta Otolaryngol 2015;135(5):440-446. https://doi.org/10.3109/00016489.2014.990056

40. Olze H, Gräbel S, Haupt H, Förster U, Mazurek B. Extra benefit of a second cochlear implant with respec to health-related quality of life and tinnitus. Otol Neurotol 2012;33(7):1169-1175. https://doi.org/10.1097/ MAO.0b013e31825e799f

41. King N, Nahm EA, Liberatos P, Shi Q, Kim AH. A new comprehensive cochlear implant questionnaire fo measuring quality of life after sequential bilateral cochlear implantation. Otol Neurotol 2014;35(3):407-413. https://doi.org/10.1097/MAO.0000000000000229

42. Westerberg BD, Lee PK, Lukwago L, Zaramba S, Bubikere S, Stewart I. Cross-sectional survey of hearing impairment and ear disease in Uganda. J Otolaryngol Head Neck Surg 2008;37(6):753-758.

Accepted 12 August 2021 